\title{
Occupation, Physical Workload Factors, and Disability Retirement as a Result of Hip Osteoarthritis in Finland, 2005-2013
}

\author{
Svetlana Solovieva, Tea Kontio, and Eira Viikari-Juntura
}

\begin{abstract}
Objective. To identify occupations with a high risk of disability retirement as a result of hip osteoarthritis (OA), and to examine the effect of physical workload factors on the occupational differences in disability retirement.

Methods. A total of 1,135,654 (49.4\% women) Finns aged 30-60 years in gainful employment were followed from 2005 to 2013 for full disability retirement as a result of hip OA. Information on pensions, occupation, and education were obtained from national registers. Physical workload was assessed by a sex-specific job exposure matrix. We calculated age-adjusted incidence rates and examined the associations of occupation, education, and physical workload factors with disability retirement using a competing risk regression model.

Results. Age-adjusted incidence rate was 25 and 22 per 100,000 person-years in men and women, respectively. Both men and women working in lower-level nonmanual and manual occupations had an elevated age-adjusted risk of disability retirement as a result of hip OA. A very high risk of disability retirement was found among male construction workers, electricians, and plumbers (HR 12.7, 95\% CI 8.4-19.7), and female professional drivers (HR 15.2, 95\% CI 7.5-30.8) as compared with professionals. After adjustment for age and education, the observed occupational differences in disability retirement were largely explained by physical workload factors among men and to a smaller extent, among women.
\end{abstract}

Conclusion. Our results suggest that education and physical workload factors appear to be the major reasons for excess disability retirement as a result of hip OA in manual occupations, particularly among men. (First Release February 1 2018; J Rheumatol 2018;45:555-62; doi:10.3899/jrheum.170748)

Key Indexing Terms:

DISABILITY

OCCUPATION

HIP OSTEOARTHRITIS

EPIDEMIOLOGY

Osteoarthritis (OA) of the hip is a major cause of pain and disability worldwide. It consumes a significant amount of healthcare resources, and impairs an individual's life ${ }^{1}$. According to the estimates of the Global Burden of Disease Study 2010, the global age-standardized prevalence of hip $\mathrm{OA}$ is $0.85 \%^{2}$, and it is rapidly increasing owing to the aging population $^{3}$. Although OA is traditionally considered an age-related disorder, the earlier stage of the disease starts at an age when people are still working ${ }^{4,5,6}$. Besides age, several

From the Finnish Institute of Occupational Health; University of Helsinki, Helsinki, Finland.

Supported by NordForsk grant number 76659 (SS), the Finnish Work Environment Fund grant number 115105 (SS), and the Academy of Finland grant number 267589 (EV-J).

S. Solovieva, PhD, Finnish Institute of Occupational Health; T. Kontio, $M D$, University of Helsinki; E. Viikari-Juntura, MD, PhD, Finnish Institute of Occupational Health.

Address correspondence to Dr. S. Solovieva, Finnish Institute of Occupational Health, P.O. Box 40, FI-00032 Helsinki, Finland. E-mail: svetlana.solovieva@ttl.fi

Full Release Article. For details see Reprints and Permissions at jrheum.org

Accepted for publication November 4, 2017. individual risk factors including previous hip injury, high body mass index, female sex, lower level of education or socioeconomic status, and occupation were reported to play a role in the development of hip OA and associated disability ${ }^{7,8,9}$.

A number of studies have looked at the association of occupational physical activities with hip $\mathrm{OA}^{10,11}$. The previous studies have been consistent in the findings on elevated risks among individuals with heavy manual work and/or employment in farming or the construction industry, especially in men. Further, longterm exposure to standing at work has a potential to increase the risk of hip $\mathrm{OA}^{11}$. Most studies of occupational risk factors were focused on male-dominated occupations. However, substantial differences in occupational exposure patterns between men and women, even within the same occupation, have been recognized $^{12}$. It is also possible that men and women are strained differently while performing the same tasks ${ }^{13}$. Studies conducted in female workers are inconsistent regarding the association of workload with hip OA. Earlier studies suggested that physically demanding work is a risk factor for

Personal non-commercial use only. The Journal of Rheumatology Copyright $\odot$ 2018. All rights reserved. 
hip OA in women ${ }^{14}$. However, in 1 study, the risk of total hip joint replacement for OA among women working in occupations with high physical demands (e.g., farmers, operators, and unskilled laborers) was even lower than that among managers and professionals ${ }^{15}$.

Although the contribution of occupation on the development of hip OA might be modest, the effect of the disease on the capacity to work is an increasing concern, owing to population aging. Hip OA was found to be associated with reduced work participation, loss of productivity $5,6,16,17$, and withdrawal from the labor force because of disability retirement as well as premature age-based retirement ${ }^{18,19}$.

Occupations may differ regarding possibilities for people with OA to perform job tasks. Differences in work-related exposure levels between occupations are well recognized ${ }^{20}$; however, scientific evidence for the effect of physically demanding work on disability retirement is limited ${ }^{21}$. Knowledge of occupational differences in disability retirement as a result of hip OA is scarce. A recent study observed a particularly high risk of disability retirement among women working in the healthcare sector and men in farming ${ }^{19}$. The sex differences in work disability because of OA, which vary by age and socioeconomic status, are acknowledged by previous research ${ }^{22,23}$. Nevertheless, it is not known whether the rate of disability retirement differs between men and women within the same occupational group.

The aim of our study was to identify occupations with a high risk of disability retirement as a result of hip OA in the Finnish population and to examine the effect of physical workload factors on occupational differences in disability retirement. We also assessed the sex differences in the incidence of disability retirement within the occupational groups.

\section{MATERIALS AND METHODS}

Setting and data sources. We carried out a population-based study using register data from a $70 \%$ random sample of the Finnish population aged 18 to 70 years living in Finland on December 31, 2004 (about 2.5 million). Because of data protection considerations, data could not be obtained for the whole Finnish population. Persons aged 30 to 60 years (as of December 2004) who had gainful jobs on January 1, 2005, were eligible for the study. We excluded persons who did not have an occupational title or those who started to receive any retirement-related benefit (full disability retirement, partial or full old-age retirement, and unemployment retirement) before January 1, 2005. Our cohort consisted of 1,135,654 persons (574,617 men and 561,037 women). Data available for the researchers were anonymous register data. Ethics approval was not required in accordance with Finnish legislation.

National register of the Finnish Centre for Pensions (FCP). Information on employee pensions, earning periods, and unemployment-related unsalaried periods were obtained from the register held by the FCP. The register covers everyone who is a Finnish citizen or permanent resident of Finland. In Finland, people with a chronic illness, disability, or injury that have been verified by a physician with a medical certificate and evaluated as causing considerable and longlasting (about 1 yr) decreased work ability are entitled to disability pension ${ }^{24}$. If there is a possibility to restore the employee's work ability through rehabilitation or treatment, a temporary pension for a fixed period can be granted by the pension provider. Temporary disability pension can often be continued after the initial period; however, a decision regarding permanent disability pension is made within 2 years. The share of temporary disability pensions has grown during the last years and in 2012, about half of all disability pensions were granted as temporary ${ }^{25}$

Disability retirement as a result of hip $O A$. The FCP register provides information on all disability retirement events with their primary and secondary diagnoses, which are classified according to the International Statistical Classification of Diseases and Related Health Problems, 10th Revision (ICD-10, Finnish version of ICD classification 1996). The outcome of our study was full-time disability retirement (either temporary or permanent) as a result of hip OA (ICD-10 code M16) in the period from January 1, 2005, to December 31, 2013.

Occupation. Information on persons' occupations held on December 31, 2004, was obtained from the Finnish Longitudinal Employer-Employee Data (FLEED) of Statistics Finland. The occupations were classified at the 4-digit level (including a few occupations coded with 5 digits) according to the Classification of Occupations 2001 by Statistics Finland, which is based on the International Standard Classification of Occupations. For the analysis, the occupations were aggregated to the 2-digit level (full details are in Supplementary Table 1, available with the online version of this article).

Physical workload factors. Heavy physical work, kneeling or squatting, manual handling of heavy loads, sitting, and standing or moving at work were estimated with a sex-specific job exposure matrix $(\mathrm{JEM})^{26}$.

Potential confounders. There is a growing awareness of the role of socioeconomic status in the development and consequences of hip $\mathrm{OA}^{9,27,28}$. Of the different socioeconomic indicators, education influences the selection of occupation, which in turn predetermines physical load factors at work that may cause hip OA and result in disability retirement. Besides the indirect effect of education through occupation, education might have a direct effect on disability retirement and an indirect effect through other factors (e.g., lifestyle factors, better access to health care, financial resources). Information on a person's education achieved by December 31, 2004, was obtained from FLEED of Statistics Finland. Education was categorized as (0) unknown; (1) primary; (2) secondary; (3) lower tertiary; and (4) higher tertiary.

Statistical analysis. We calculated age-adjusted (age groups 30-39, 40-49, $50-59$, and $\geq 60 \mathrm{yrs}$ ) incidence rates (IR) per 100,000 person-yrs) of disability retirement by occupational group, and estimated $95 \%$ CI using a Poisson distribution. The persons were followed from January 1, 2005, until December 31, 2013, for the first occurrence of temporary or permanent full-disability retirement as a result of hip OA. We calculated incidence rate ratios (IRR) and their $95 \% \mathrm{CI}$ to examine the overall and occupation-specific sex differences in IR of disability retirement. The reference group consisted of men. To test the association between occupation and temporary or permanent full-disability retirement, we estimated HR and their $95 \% \mathrm{CI}$ using competing risk regression model (stcrreg, STATA version 14). We accounted for the effect on the outcome of the following competing risks: full-disability retirement because of causes other than hip OA, old-age retirement, and death. The reference group consisted of professionals (including physical, mathematical, and engineering science professionals, life science and health professionals, as well as others). The contribution of education and physical workload factors to the associations between occupation and disability retirement was examined by consecutively including education (Model 2) and physical workload factors (Model 3) with the age-adjusted model (Model 1). To estimate the contribution of the explanatory factors to the observed statistically significant associations, we calculated the percentage attenuation of HR for all occupations (with professionals as reference) after adjustment, using the following formula ${ }^{29}$, where

$$
\begin{gathered}
\mathrm{i}=\text { Model } 1 \text { or 2: proportion explained }(\%)=\left(\mathrm{HR}_{\text {Model_i }}\right. \\
\left.-\mathrm{HR}_{\text {Model_i+1 }}\right) /\left(\mathrm{HR}_{\text {Model_i }}-1\right) \times 100
\end{gathered}
$$

The analyses were made for men and women separately.

Personal non-commercial use only. The Journal of Rheumatology Copyright @ 2018. All rights reserved. 


\section{RESULTS}

Description of sample. In total, 1,135,654 persons (49.4\% women) met the inclusion criteria. At baseline, women were slightly older ( $45.3 \pm 8.4$ vs $44.6 \pm 8.3 \mathrm{yrs})$, had more frequently attained tertiary education ( $30.5 \%$ vs $16.7 \%)$, and were more often employed in the public sector $(46.2 \%$ vs $17.1 \%$ ) than men. All manual occupations except building caretakers, cleaners, assistant nurses, and kitchen workers were male dominated, while all lower-level nonmanual occupations, except physical and engineering science technicians, were female dominated (Table 1).

IR of full disability retirement. From January 1, 2005, until December 31, 2013, a total of 2212 persons (1180 men and 1032 women) had disability retirement as a result of hip OA. The overall age-adjusted IR of full disability retirement was lower in women than men (22 and 25 per 100,000 person-yrs, respectively; IRR $=0.88,95 \%$ CI 0.81-0.96; Table 2). Among men, occupations with higher IR than the population average included construction workers; electricians; plumbers; agricultural and fishery workers; unskilled transport, construction, and manufacturing workers; metal and machinery workers, and professional drivers. Among women, occupations with higher IR than the population average included professional drivers, agricultural and fishery workers, building caretakers, cleaners, assistant nurses, kitchen workers, and service workers.

Physical workload factors and disability retirement. In the age-adjusted models, all physical load factors were statistically significantly associated with disability retirement as a result of hip OA in both sexes (Table 3). When all factors were included into the model simultaneously, the associations for kneeling or squatting (in men), heavy lifting, and standing or moving (in women) lost their statistical significance. For example, the age-adjusted HR for heavy lifting among women was 1.89 (95\% CI 1.58-2.27), and when all physical workload factors were included into the model, the HR dropped to 1.08 (95\% CI 0.87-1.34).

Risk of disability retirement by occupation. Among men, as compared to professionals, the age-adjusted risk of disability retirement was increased in all occupations except managers and teaching professionals (Table 4). Construction workers, electricians, and plumbers had the highest risk, and unskilled transport, construction, and manufacturing workers had the second highest risk of disability retirement $(\mathrm{HR}=12.7,95 \%$ CI 8.44-19.7 and 10.6, 95\% CI 6.75-16.7, respectively).

Among women, as compared to the professionals, the age-adjusted risk of disability retirement was elevated in all but teaching professionals, physical and engineering science technicians, and construction workers, electricians, and plumbers (Table 5). The highest risk of disability retirement was observed for professional drivers (HR 15.2, 95\% CI 7.47-30.8).

In both sexes, adjustment for education largely attenuated the occupational differences in disability retirement (Table 4 and Table 5). Among men, the reduction in the risk varied between $32.1 \%$ (environmental officers and nurses) and $56.8 \%$ (chemical, wood, and metal processing workers). A larger variation in the proportion explained by education was seen among women, from $14.5 \%$ (environmental officers and nurses) to $66.1 \%$ (customer service clerks).

Table 1. Distribution of occupational groups among 30- to 60-year-old men and women stratified by sex and occupational group.

\begin{tabular}{|c|c|c|c|c|c|}
\hline Occupational Groups & $\%$ & Age & $\%$ & Age & $\begin{array}{l}\text { Percentage } \\
\text { of Women }\end{array}$ \\
\hline \multicolumn{6}{|l|}{ Upper-level nonmanual } \\
\hline Professionals & 13.5 & 43.9 & 10.2 & 44.2 & 42.6 \\
\hline Teaching professionals & 4.0 & 45.2 & 8.3 & 44.0 & 66.9 \\
\hline \multicolumn{6}{|l|}{ Lower-level nonmanual } \\
\hline Finance and sales associate professionals, and administrative secretaries & 8.7 & 44.6 & 12.6 & 45.1 & 58.6 \\
\hline Office clerks & 3.2 & 44.7 & 10.6 & 46.0 & 76.6 \\
\hline Customer service clerks & 0.3 & 41.7 & 3.2 & 46.7 & 91.8 \\
\hline Service workers & 3.9 & 42.4 & 18.7 & 45.5 & 82.5 \\
\hline Shop workers & 2.3 & 42.8 & 5.0 & 43.8 & 67.6 \\
\hline \multicolumn{6}{|l|}{ Manual occupations } \\
\hline Chemical, wood, and metal processing workers & 3.3 & 44.6 & 0.8 & 45.6 & 18.3 \\
\hline Machine operators and assemblers & 4.6 & 43.4 & 3.2 & 45.6 & 40.6 \\
\hline Professional drivers & 8.0 & 45.1 & 0.5 & 45.9 & 5.5 \\
\hline Building caretakers, cleaners, assistant nurses, and kitchen workers & 2.9 & 45.2 & 7.8 & 47.5 & 72.8 \\
\hline Unskilled transport, construction, and manufacturing workers & 3.2 & 44.1 & 1.2 & 45.7 & 25.8 \\
\hline
\end{tabular}

Personal non-commercial use only. The Journal of Rheumatology Copyright @ 2018 . All rights reserved. 
Table 2. Age-adjusted IR per 100,000 person-years and 95\% CI of full disability retirement as a result of hip OA among 30- to 60-year-old men and women by occupational group, 2005-2013.

\begin{tabular}{|c|c|c|c|c|c|c|c|c|}
\hline \multirow[t]{2}{*}{ Occupations } & \multicolumn{3}{|c|}{ Men, $\mathrm{n}=574,617$} & \multicolumn{3}{|c|}{ Women, $\mathrm{n}=561,037$} & \multirow[t]{2}{*}{$\mathrm{IRR}^{*}$} & \multirow[t]{2}{*}{$95 \% \mathrm{CI}$} \\
\hline & No. Events & $\mathrm{IR}_{\mathrm{m}}$ & $95 \% \mathrm{CI}$ & No. Events & $\mathrm{IR}_{\mathrm{w}}$ & $95 \% \mathrm{CI}$ & & \\
\hline Managers & 19 & 7 & $3-16$ & 13 & 10 & $4-28$ & 1.43 & $0.71-2.89$ \\
\hline Teaching professionals & 6 & 3 & $1-12$ & 25 & 6 & $3-14$ & 2.00 & $0.82-4.88$ \\
\hline Physical and engineering science technicians & 52 & 13 & $8-22$ & 7 & 8 & $2-28$ & 0.62 & $0.28-1.35$ \\
\hline Environmental officers and nurses & 11 & 24 & $8-78$ & 50 & 14 & $8-27$ & 0.58 & $0.30-1.12$ \\
\hline Office clerks & 26 & 17 & $8-41$ & 62 & 12 & $8-21$ & 0.71 & $0.45-1.12$ \\
\hline Customer service clerks & 0 & - & - & 18 & 12 & $5-30$ & - & \\
\hline Service workers & 51 & 28 & $15-53$ & 313 & 37 & $29-47$ & 1.32 & $0.98-1.78$ \\
\hline Shop workers & 24 & 22 & $10-53$ & 61 & 28 & $17-50$ & 1.27 & $0.79-2.04$ \\
\hline Agricultural and fishery workers & 135 & 49 & $35-70$ & 80 & 57 & 37-93 & 1.16 & $0.88-1.53$ \\
\hline Construction workers, electricians, and plumbers & 208 & 56 & $43-75$ & 3 & 11 & $2-81$ & 0.20 & $0.06-0.61$ \\
\hline Professional drivers & 141 & 39 & $28-56$ & 14 & 65 & $27-162$ & 1.67 & $0.96-2.89$ \\
\hline Building caretakers, cleaners, assistant nurses, and kitchen workers & 56 & 43 & $26-75$ & 194 & 58 & $44-79$ & 1.35 & $1.00-1.82$ \\
\hline Unskilled transport, construction, and manufacturing workers & 86 & 45 & $29-75$ & 18 & 39 & $19-84$ & 0.87 & $0.52-1.44$ \\
\hline All & 1180 & 25 & $22-28$ & 1032 & 22 & $20-26$ & 0.88 & $0.81-0.96$ \\
\hline
\end{tabular}

*IRR calculated as $\mathrm{IR}_{\mathrm{w}} / \mathrm{IR}_{\mathrm{m}}$. IR: incidence rate; OA: osteoarthritis; IRR: IR ratio.

Table 3. Associations between physical workload factors and disability retirement as a result of hip OA among 30- to 60-year-old men and women. Values are $\mathrm{HR}$ and $95 \% \mathrm{CI}$.

\begin{tabular}{|c|c|c|c|c|c|c|c|c|}
\hline \multirow[t]{2}{*}{ Physical Workload Factors } & \multicolumn{4}{|c|}{ Men } & \multicolumn{4}{|c|}{ Women } \\
\hline & $\mathrm{HR}^{\mathrm{a}}$ & $95 \% \mathrm{CI}$ & $\mathrm{HR}^{\mathrm{b}}$ & $95 \% \mathrm{CI}$ & $\mathrm{HR}^{\mathrm{a}}$ & $95 \% \mathrm{CI}$ & $\mathrm{HR}^{\mathrm{b}}$ & $95 \% \mathrm{CI}$ \\
\hline Heavy physical work & 2.42 & $2.16-2.72$ & 1.34 & $1.10-1.64$ & 2.24 & $1.97-2.55$ & 1.65 & $1.39-1.95$ \\
\hline Heavy lifting & 2.34 & $2.07-2.65$ & 1.23 & $1.02-1.48$ & 1.89 & $1.58-2.27$ & 1.08 & $0.87-1.34$ \\
\hline Sitting & 0.28 & $0.24-0.34$ & 0.43 & $0.34-0.54$ & 0.35 & $0.29-0.42$ & 0.48 & $0.39-0.58$ \\
\hline Standing or moving & 2.43 & $2.14-2.75$ & 1.24 & $1.04-1.48$ & 1.75 & $1.55-1.98$ & 1.13 & $0.98-1.29$ \\
\hline
\end{tabular}

${ }^{a}$ Adjusted for age. ${ }^{b}$ Adjusted for age and mutually adjusted (i.e., each physical workload factor is adjusted for other physical workload factors in the model). OA: osteoarthritis.

The effect of physical workload factors on occupational differences in disability retirement. The combined contribution of physical workload factors to the risk of disability retirement in men was higher among construction workers, electricians, and plumbers $(87.8 \%)$, metal and machinery workers $(80.0 \%)$, and agricultural and fishery workers (76.9) than among the other occupational groups (Table 4). The physical workload factors explained most of the excess risk of disability retirement in these 3 occupational groups. However, after adjustment for education and physical workload factors, the risk of disability retirement remained statistically significant for most of the other occupations.

In general, the contribution of physical workload factors on occupational differences in disability retirement was much lower among women than men (Table 4 and Table 5). Among managers and office clerks, adjustment for physical workload factors increased the risk of disability retirement as a result of hip OA.

The physical workload that explained the highest contribution to the excess risk for most of the male occupations was kneeling and squatting (Table 4). The proportion of the risk explained was especially high for the construction workers, electricians, and plumbers (78.9\%). Among women, the contribution of each of the single physical workload factors was rather small for most of the occupations (Table 5).

Sex differences in occupation-specific risk of disability retirement. Female chemical, wood, and metal processing workers, machine operators and assemblers, as well as building caretakers, cleaners, assistant nurses, and kitchen workers had statistically significantly higher age-adjusted IR of disability retirement than men in the corresponding occupational groups (Table 2). However, in the competing 
Table 4. HR and 95\% CI of full disability retirement as a result of hip OA among 30- to 60-year-old men by occupational group, $2005-2013$.

\begin{tabular}{|c|c|c|c|c|c|c|c|c|c|c|c|c|c|}
\hline \multirow[t]{2}{*}{ Occupational Groups } & \multicolumn{2}{|c|}{ Model 1} & \multicolumn{3}{|c|}{ Model 2} & \multicolumn{2}{|c|}{ Model 3} & \multirow{2}{*}{$\begin{array}{l}\text { All Factors } \\
\text { PRE }^{* b}\end{array}$} & \multirow{2}{*}{$\begin{array}{l}\text { s, Heavy } \\
\text { Physical } \\
\text { Work, PRE* c }\end{array}$} & \multirow{2}{*}{$\begin{array}{c}\text { Kneeling or } \\
\text { Squatting, } \\
\text { PRE* b }^{*}\end{array}$} & \multirow{2}{*}{$\begin{array}{l}\text { Heavy } \\
\text { Lifting, } \\
\text { PRE*b }^{*}\end{array}$} & \multirow{2}{*}{$\begin{array}{l}\text { Sitting, } \\
\text { PRE* b }^{*}\end{array}$} & \multirow{2}{*}{$\begin{array}{c}\text { Standing } \\
\text { or Moving, } \\
\text { PRE b }^{*}\end{array}$} \\
\hline & HR & $95 \% \mathrm{CI}$ & HR & $95 \% \mathrm{CI}$ & $\mathrm{PRE}^{* \mathrm{a}}$ & HR & $95 \% \mathrm{CI}$ & & & & & & \\
\hline Managers & 1.39 & $0.77-2.51$ & 1.26 & $0.70-2.27$ & NA & 1.17 & $0.65-2.10$ & NA & NA & NA & NA & NA & NA \\
\hline Professionals & 1.00 & & 1.00 & & & 1.00 & & NA & NA & NA & NA & NA & NA \\
\hline Teaching professionals & 0.69 & $0.28-1.67$ & 0.69 & $0.28-1.68$ & NA & 0.64 & $0.26-1.58$ & NA & NA & NA & NA & NA & NA \\
\hline $\begin{array}{l}\text { Environmental officers } \\
\text { and nurses }\end{array}$ & 6.39 & $3.16-12.9$ & 4.66 & $2.30-9.44$ & 32.1 & 3.80 & $1.78-8.10$ & 23.5 & 10.1 & 13.9 & 5.7 & 26.5 & 16.1 \\
\hline \multicolumn{14}{|c|}{ Finance and sales associate professionals, and administrative } \\
\hline secretaries & 2.84 & $1.77-4.56$ & 1.85 & $1.15-2.98$ & 53.8 & 1.65 & $1.01-2.69$ & 23.5 & 12.9 & 11.8 & 5.9 & 15.3 & 15.3 \\
\hline Office clerks & 4.02 & $2.33-6.92$ & 2.32 & $1.32-4.10$ & 56.3 & 1.91 & $1.07-3.45$ & 31.1 & 30.3 & 10.6 & 7.6 & 18.9 & 12.1 \\
\hline Customer service clerks & NA & & NA & & NA & NA & & NA & NA & NA & NA & NA & NA \\
\hline \multicolumn{14}{|c|}{ Construction workers, electricians, } \\
\hline \multicolumn{14}{|l|}{ Metal and machinery } \\
\hline Craft workers & 8.16 & $4.88-13.6$ & 4.54 & $2.66-7.73$ & 50.6 & 2.85 & $1.58-5.16$ & 47.7 & 29.4 & 37.6 & 13.8 & 26.0 & 15.5 \\
\hline \multicolumn{11}{|c|}{ Chemical, wood, and metal } & 21.7 & 30.9 & 25.1 \\
\hline $\begin{array}{l}\text { Machine operators and } \\
\text { assemblers }\end{array}$ & 6.59 & $4.13-10.5$ & 3.50 & $2.14-5.71$ & 55.3 & 2.34 & $1.32-4.15$ & 46.4 & 32.8 & 31.6 & 20.8 & 30.0 & 24.8 \\
\hline Professional drivers & 8.44 & $5.55-12.8$ & 4.38 & $2.81-6.84$ & 54.6 & 3.56 & $2.15-5.91$ & 24.3 & 34.0 & 14.2 & 21.3 & 17.8 & 0.9 \\
\hline \multicolumn{14}{|c|}{ Building caretakers, cleaners, assistant nurses, and } \\
\hline kitchen workers & 9.15 & $5.75-14.6$ & 4.90 & $3.00-7.99$ & 52.2 & 2.58 & $1.39-4.80$ & 59.5 & 35.9 & 42.3 & 11.3 & 34.4 & 23.1 \\
\hline
\end{tabular}

Model 1: adjusted for age. Model 2: adjusted for age and education. Model 3: adjusted for age, education, and all physical workload factors. *Reference group: professionals. ${ }^{a} \mathrm{PRE}=$ percentage of attenuation of $\mathrm{HR}$ after adjustment: $\left(\mathrm{HR}_{\mathrm{Model} 2}-\mathrm{HR}_{\mathrm{Model} 1}\right) /\left(\mathrm{HR}_{\mathrm{Model} 1}-1\right) \times 100 \%$. ${ }^{\text {b PRE }}=$ percentage of attenuation of $\mathrm{HR}$ after adjustment: $\left(\mathrm{HR}_{\text {Model 3 }}-\mathrm{HR}_{\text {Model 2 }}\right) /\left(\mathrm{HR}_{\text {Model } 2}-1\right) \times 100 \% .{ }^{c} \mathrm{PRE}=$ percentage of attenuation of $\mathrm{HR}$ after adjustment: $\left(\mathrm{HR}_{\text {Model } \mathrm{X}}-\mathrm{HR}_{\mathrm{Model} 2}\right) /\left(\mathrm{HR}_{\mathrm{Model} 2}\right.$ $-1) \times 100 \%$, where Model X is adjusted for age, education, and the physical workload factor in question; HR for the Model X not shown. OA: osteoarthritis; PRE: proportion explained (\%); NA: not applicable.

risk analysis, this difference lost its statistical significance after adjustment for education and physical workload factors.

\section{DISCUSSION}

Our prospective nationwide register-based study showed considerable occupational differences in the 9-year IR of disability retirement as a result of hip OA in both sexes. Overall, the age-adjusted IR of disability retirement was higher in men than women. As compared to the professionals, the age-adjusted risk of disability retirement was elevated among men working in all lower-level nonmanual and manual occupations. A similar phenomenon was observed in women, except for female construction workers, electricians, and plumbers. In manual occupations, the observed occupational differences in disability retirement were largely explained by educational level in both men and women. The physical workload factors completely mediated the association among male agricultural and fishery workers, construc- tion workers, electricians, and plumbers, as well as metal and machinery workers, and female teaching professionals. These findings suggest that the risk of disability retirement as a result of hip OA in these occupations could be eliminated if the physical workload factors were at the level of those among professionals. Nevertheless, even after adjustment for education and physical workload factors, the risk of disability retirement as a result of hip OA remained very high ( $>4$-fold) among female professional drivers, and chemical, wood, and metal processing workers, as compared with the female professionals.

Several previous studies have focused on the association between occupation and hip OA, most of them among men. Epidemiologic evidence on a strong graded effect of longterm exposure to heavy lifting, as well as standing at work, on hip $\mathrm{OA}^{11}$ suggests that people engaged in occupational activities with unusual stress on the hip are at higher risk of developing hip OA. The occupational groups with excess prevalence of

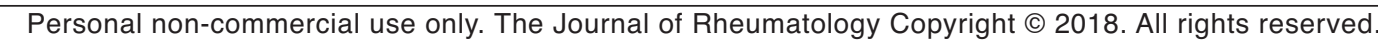


Table 5. HR and 95\% CI of full disability retirement as a result of hip OA 2005-2013 among 30- to 60-year-old women by occupational group.

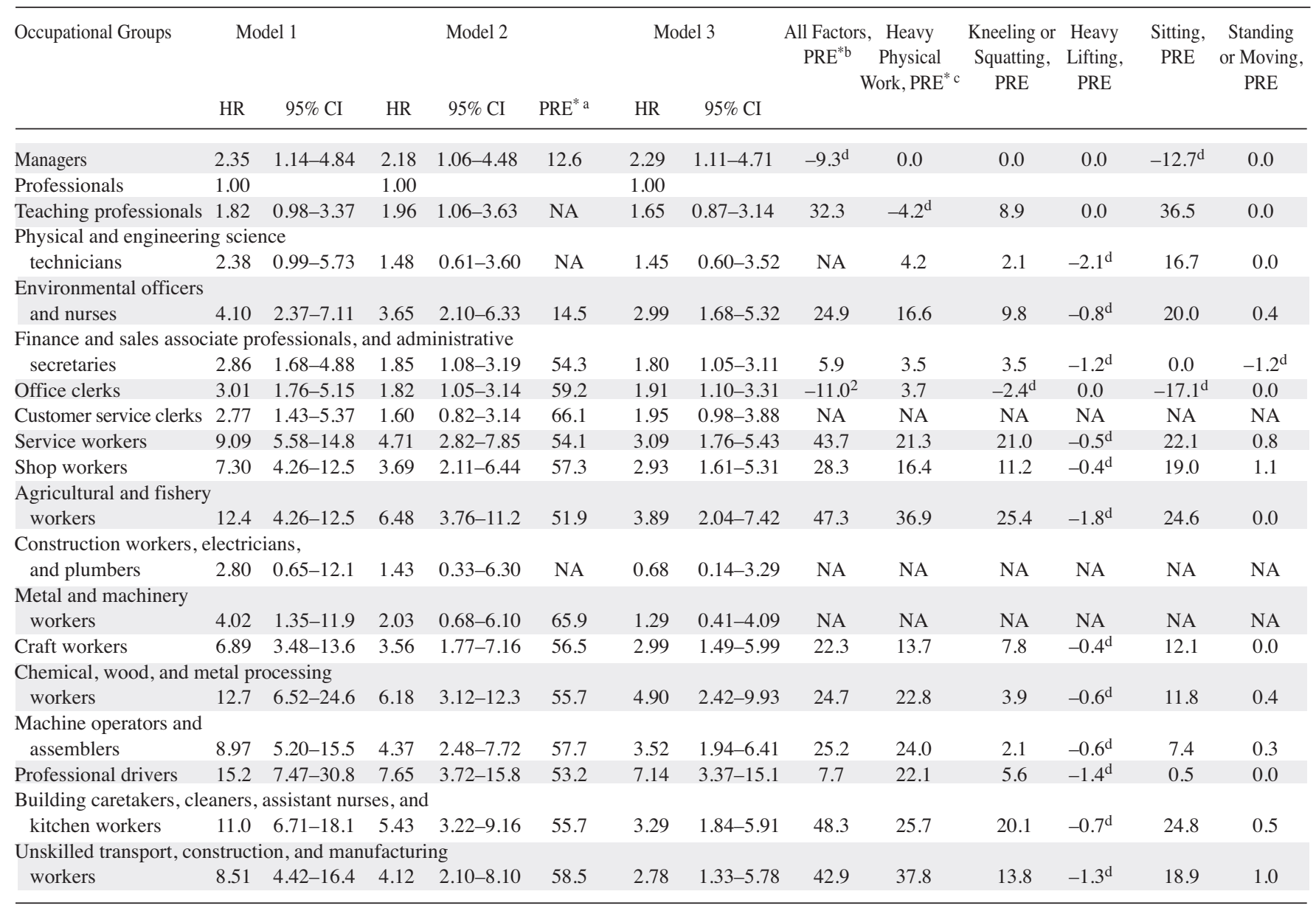

Model 1: adjusted for age. Model 2: adjusted for age and education. Model 3: adjusted for age, education, and all physical workload factors. *Reference group: professionals. ${ }^{\text {PPRE }}=$ percentage of attenuation of $\mathrm{HR}$ after adjustment: $\left(\mathrm{HR}_{\text {Model } 2}-\mathrm{HR}_{\mathrm{Model} 1}\right) /\left(\mathrm{HR}_{\mathrm{Model} 1}-1\right) \times 100 \%$. ${ }^{\text {bPRE}}=$ percentage of attenuation of $\mathrm{HR}$ after adjustment: $\left(\mathrm{HR}_{\text {Model 3 }}-\mathrm{HR}_{\text {Model 2 }}\right) /\left(\mathrm{HR}_{\text {Model 2 }}-1\right) \times 100 \%$. ${ }^{c} \mathrm{PRE}=$ percentage of attenuation of $\mathrm{HR}$ after adjustment: $\left(\mathrm{HR}_{\text {Model X }}-\mathrm{HR}_{\text {Model } 2}\right) /\left(\mathrm{HR}_{\text {Model } 2}\right.$ $-1) \times 100 \%$, where Model X is adjusted for age, education, and the physical workload factor in question; HR for the Model X not shown. ${ }^{\mathrm{N}}$ Negative sign indicates an increase in HR after adjustment. OA: osteoarthritis; PRE: proportion explained (\%); NA: not applicable.

hip OA, identified by previous studies, include farmers and construction workers ${ }^{30}$. It has been estimated that every third incident case of surgically treated hip OA among workers in the construction industry is likely caused by physical load at work ${ }^{31}$.

Even though a low prevalence of hip OA in the working age population suggests that only a minority of hip OA could be attributed to work, the disease may influence work retention. The findings of the few studies on the effect of hip OA on work participation are inconsistent. Work participation of middle-aged Dutch people with early OA was similar to the general population ${ }^{32}$. On the contrary, another study in a nationally representative sample of 30- to 99-year-old Finns reported a $20 \%$ reduction in work participation among 30 - to 59-year-old men with hip OA, as compared with persons without the disease ${ }^{5}$.

To our knowledge, only 1 study ${ }^{19}$ examined the occupational differences in disability retirement, though in a limited set of occupations. We estimated the risk of disability retirement across 19 occupational groups (including all nonmanual and manual occupations held by Finns in 2005). Our results on excessive risk of disability retirement among female service workers, as well as building caretakers, cleaners, assistant nurses, and kitchen workers, and male agricultural and fishery workers are in line with the findings by Hubertsson, et al $^{19}$. However, in contrast to their findings, we also observed an excess risk of disability retirement among male construction workers, electricians, and plumbers, and metal and machinery workers, as well as professional drivers.

Previous studies suggested that excess disability retirement as a result of musculoskeletal diseases in manual occupations is largely attributed to unfavorable physical workload factors and limited possibilities for adjusting the work environment to enable continuing at work in spite of reduced work ability ${ }^{33,34,35}$. In agreement with the findings 
of those studies, we found a considerable contribution of physical workload factors on occupational differences in disability retirement, especially among men. Our results suggest that $24-88 \%$ of cases of disability retirement in men and $6-48 \%$ in women could be attributed to physical workload factors.

Knowledge of sex differences in the occurrence of hip OA is inconsistent. In a systematic review by Pereira, et al ${ }^{36}$, no sex differences were found; however, the Global Burden of Disease 2010 study reported a higher global age-standardized prevalence of hip OA in women than in $\mathrm{men}^{2}$. Even though hip OA was found to be more prevalent in working-age men than women, a larger proportion of women with hip OA (78\%) than men $(67 \%)$ managed to continue working ${ }^{5}$. We observed a lower overall IR of disability retirement in working-age women compared to men. This may be a result of men having higher levels and higher co-occurrence of physical workload factors. In fact, we found that the contribution of physical workload factors was higher in men compared with women. Although the sex differences in disability retirement varied widely across occupational groups, they became negligible after controlling for education and physical workload factors.

Our results pointed to a substantial influence of physical workload factors on occupational differences in disability retirement, particularly among men. However, the risk of disability retirement in female professional drivers, and chemical, wood, and metal processing workers remained high as compared with professionals, even after adjustment for education and physical workload factors. These findings suggest that in these occupations, risk factors other than those examined in our study (e.g., obesity, smoking, psychosocial work-related factors) affect the ability of persons to remain at work.

The strengths of our study are a large, nationally representative sample of the Finnish working population, a relatively long followup time, and the availability of physical work exposures for each occupation from a sex-specific job exposure matrix. Further, to control for the potential effect of competing risks (e.g., disability retirement as a result of causes other than hip OA, mortality) on the outcome of interest, we conducted a competing risk analysis. However, despite assessment of the physical workload factors by a sex-specific JEM, there may have been a nondifferential misclassification of the exposures, particularly in occupations with larger within-occupation differences in the physical workload factors. As a result, the adjustment for physical workload factors led to smaller attenuation of HR. Therefore, the remaining elevated risk of disability retirement for some occupations may still be a result of physical workload factors that were not collected by the JEM. Moreover, the used registers did not include information on the length the jobs were held. If physical workload causes hip OA, and persons with hip OA and physically demanding jobs changed to less physically demanding jobs, the observed occupational differences in disability retirement might have been underestimated. Finally, because of the register-based design of our study, we were not able to control for lifestyle factors in our analyses.

Our study provides comprehensive information on occupational differences in disability retirement as a result of hip OA in both sexes and across a broad range of occupations. Men and women working in lower-level nonmanual and manual occupations are at higher risk of disability retirement compared to professionals. Our results suggest that in addition to education, physical workload factors appear to be the major reasons for excess disability retirement, particularly among men. The findings of our study imply that to increase work participation of manual workers with hip problems, interventions are needed to reduce the physical workload, especially kneeling or squatting. If the adjustment of the work environment is not feasible, a change to a less physically demanding job could be recommended.

\section{ONLINE SUPPLEMENT}

Supplementary material accompanies the online version of this article.

\section{REFERENCES}

1. Xie F, Kovic B, Jin X, He X, Wang M, Silvestre C. Economic and humanistic burden of osteoarthritis: a systematic review of large sample studies. Pharmacoeconomics 2016;34:1087-100.

2. Cross M, Smith E, Hoy D, Nolte S, Ackerman I, Fransen M, et al. The global burden of hip and knee osteoarthritis: estimates from the global burden of disease 2010 study. Ann Rheum Dis 2014;73:1323-30.

3. Martel-Pelletier J, Barr AJ, Cicuttini FM, Conaghan PG, Cooper C, Goldring MB, et al. Osteoarthritis. Nat Rev Dis Primers 2016;2:16072.

4. Rossignol M, Leclerc A, Allaert FA, Rozenberg S, Valat JP, Avouac $\mathrm{B}$, et al. Primary osteoarthritis of hip, knee, and hand in relation to occupational exposure. Occup Environ Med 2005;62:772-7.

5. Kaila-Kangas L, Arokoski J, Impivaara O, Viikari-Juntura E, Leino-Arjas P, Luukkonen R, et al. Associations of hip osteoarthritis with history of recurrent exposure to manual handling of loads over $20 \mathrm{~kg}$ and work participation: a population-based study of men and women. Occup Environ Med 2011;68:734-8.

6. Palmer KT, Goodson N. Ageing, musculoskeletal health and work. Best Pract Res Clin Rheumatol 2015;29:391-404.

7. Buckwalter JA, Saltzman C, Brown T. The impact of osteoarthritis: implications for research. Clin Orthop Relat Res 2004;427 Suppl:S6-15.

8. Dagenais S, Garbedian S, Wai EK. Systematic review of the prevalence of radiographic primary hip osteoarthritis. Clin Orthop Relat Res 2009;467:623-37.

9. Cleveland RJ, Luong ML, Knight JB, Schoster B, Renner JB, Jordan JM, et al. Independent associations of socioeconomic factors with disability and pain in adults with knee osteoarthritis. BMC Musculoskelet Disord 2013;14:297.

10. Lievense A, Bierma-Zeinstra S, Verhagen A, Verhaar J, Koes B. Influence of work on the development of osteoarthritis of the hip: a systematic review. J Rheumatol 2001;28:2520-8.

11. Sulsky SI, Carlton L, Bochmann F, Ellegast R, Glitsch U, Hartmann $\mathrm{B}$, et al. Epidemiological evidence for workload as a risk factor for osteoarthritis of the hip: a systematic review. PLoS One 2012; $7: \mathrm{e} 31521$.

Personal non-commercial use only. The Journal of Rheumatology Copyright (C) 2018. All rights reserved. 
12. Eng A, 't Mannetje A, McLean D, Ellison-Loschmann L, Cheng S, Pearce N. Gender differences in occupational exposure patterns. Occup Environ Med 2011;68:888-94.

13. Silverstein B, Fan ZJ, Smith CK, Bao S, Howard N, Spielholz P, et al. Gender adjustment or stratification in discerning upper extremity musculoskeletal disorder risk? Scand J Work Environ Health 2009;35:113-26.

14. Vingård E, Alfredsson L, Malchau H. Osteoarthrosis of the hip in women and its relation to physical load at work and in the home. Ann Rheum Dis 1997;56:293-8.

15. Franklin J, Ingvarsson T, Englund M, Lohmander S. Association between occupation and knee and hip replacement due to osteoarthritis: a case-control study. Arthritis Res Ther 2010;12:R102.

16. Bieleman HJ, Bierma-Zeinstra SM, Oosterveld FG, Reneman MF, Verhagen AP, Groothoff JW. The effect of osteoarthritis of the hip or knee on work participation. J Rheumatol 2011;38:1835-43.

17. Andersen S, Thygesen LC, Davidsen M, Helweg-Larsen K Cumulative years in occupation and the risk of hip or knee osteoarthritis in men and women: a register-based follow-up study. Occup Environ Med 2012;69:325-30.

18. Muchmore L, Lynch WD, Gardner HH, Williamson T, Burke T. Prevalence of arthritis and associated joint disorders in an employed population and the associated healthcare, sick leave, disability, and workers' compensation benefits cost and productivity loss of employers. J Occup Environ Med 2003;45:369-78.

19. Hubertsson J, Turkiewicz A, Petersson IF, Englund M. Understanding occupation, sick leave, and disability pension due to knee and hip osteoarthritis from a sex perspective. Arthritis Care Res 2017;69:226-33.

20. Niedhammer I, Chastang JF, David S, Kelleher C. The contribution of occupational factors to social inequalities in health: Findings from the national French SUMER survey. Soc Sci Med 2008;67:1870-81.

21. Allebeck P, Mastekaasa A. Swedish Council on Technology Assessment in Health Care (SBU). Chapter 5. Risk factors for sick leave - general studies. Scand J Public Health Suppl 2004; 63:49-108.

22. Holte HH, Tambs K, Bjerkedal T. Manual work as predictor for disability pensioning with osteoarthritis among the employed in Norway 1971-1990. Int J Epidemiol 2000;29:487-94.

23. Hubertsson J, Petersson IF, Thorstensson CA, Englund M. Risk of sick leave and disability pension in working-age women and men with knee osteoarthritis. Ann Rheum Dis 2013;72:401-5.

24. Gould R. Disability pensions in Finland. In: Prinz C, editor. European disability pension policies. Vienna: Ashgate; 2003: 165-96.
25. Finnish Centre for Pensions. Pensioners and insured in Finland 2012. Official Statistics of Finland, Social Protection. Helsinki: Finnish Centre for Pensions and Keva; 2013.

26. Solovieva S, Pehkonen I, Kausto J, Miranda H, Shiri R, Kauppinen $\mathrm{T}$, et al. Development and validation of a job exposure matrix for physical risk factors in low back pain. PLoS One 2012;7:e48680.

27. Reyes C, Garcia-Gil M, Elorza JM, Mendez-Boo L, Hermosilla E, Javaid MK, et al. Socio-economic status and the risk of developing hand, hip or knee osteoarthritis: a region-wide ecological study. Osteoarthritis Cartilage 2015;23:1323-9.

28. Wetterholm M, Turkiewicz A, Stigmar K, Hubertsson J, Englund M. The rate of joint replacement in osteoarthritis depends on the patient's socioeconomic status. Acta Orthop 2016;87:245-51

29. Hafeman DM. "Proportion explained": a causal interpretation for standard measures of indirect effect? Am J Epidemiol 2009; 170:1443-8.

30. Harris EC, Coggon D. Hip osteoarthritis and work. Best Pract Res Clin Rheumatol 2015;29:462-82.

31. Järvholm B, From C, Lewold S, Malchau H, Vingård E. Incidence of surgically treated osteoarthritis in the hip and knee in male construction workers. Occup Environ Med 2008;65:275-8.

32. Bieleman HJ, Oosterveld FG, Oostveen JC, Reneman MF, Groothoff JW. Work participation and health status in early osteoarthritis of the hip and/or knee: a comparison between the Cohort Hip and Cohort Knee and the Osteoarthritis Initiative. Arthritis Care Res 2010;62:683-9.

33. Kärkkäinen S, Pitkäniemi J, Silventoinen K, Svedberg P, Huunan-Seppälä A, Koskenvuo K, et al. Disability pension due to musculoskeletal diagnoses: importance of work-related factors in a prospective cohort study of Finnish twins. Scand J Work Environ Health 2013;39:343-50.

34. Järvholm B, Stattin M, Robroek SJ, Janlert U, Karlsson B, Burdorf A. Heavy work and disability pension - a long term follow-up of Swedish construction workers. Scand J Work Environ Health 2014;40:335-42.

35. Robroek SJ, Järvholm B, van der Beek AJ, Proper KI, Wahlström J, Burdorf A. Influence of obesity and physical workload on disability benefits among construction workers followed up for 37 years. Occup Environ Med 2017;74:621-7.

36. Pereira D, Peleteiro B, Araújo J, Branco J, Santos RA, Ramos E. The effect of osteoarthritis definition on prevalence and incidence estimates: a systematic review. Osteoarthritis Cartilage 2011;19:1270-85. 